\title{
Mississippi Partnerships for Employment: Collaborating for systems change
}

\author{
Charles Hughes Jr* \\ Mississippi Council on Developmental Disabilities, Jackson, MS, USA
}

Revised/Accepted April 2017

\begin{abstract}
.
BACKGROUND: Employment outcomes in Mississippi for people with disabilities vary widely. In 2011, the Administration on Intellectual and Developmental Disabilities announced the availability of a grant to expand community employment in integrated settings for youth and young adults with intellectual and developmental disabilities.

OBJECTIVE: The purpose of this article is to provide an overview of the development, implementation, and outcomes of the Mississippi Partnerships for Employment for Youth and Young Adults with Intellectual and Developmental Disabilities (MSPE) grant, a Project of National Significance funded by the Administration on Intellectual and Developmental Disabilities from October 2011 to September 2016. The goal of the project was to build capacity and create sustainable systems change that improves employment outcomes for youth and young adults with intellectual and developmental disabilities in the state. CONCLUSION: MSPE established a Consortium of self-advocates and state system representatives to focus on real changes within and among agencies to increase competitive employment outcomes. In addition, two work groups were developed: one for identifying barriers and determining how to improve access to employment for the target group, and one to focus on training needs and best practices. Additionally, through pilot projects, two school districts demonstrated improved transition services outcomes and employment experiences, and one disability organization sought to increase reimbursements for customized employment for service providers. Other key activities, outcomes, and sustainability efforts will also be examined.
\end{abstract}

Keywords: Employment, intellectual disabilities, developmental disabilities, transition, systems change

\section{Introduction}

Societal expectation holds that children will grow up, complete high school, possibly go to college, and become contributing members of society and the workforce. As parents plan for their children's futures and youth and young adults plan for their own lives, employment and the opportunities it provides typically receive great emphasis and consideration. Planning for the future is not limited to individuals and their families. State governments plan and develop education, health care, and employment policies, programs, and services to best meet the needs of their residents. Youth and young adults

\footnotetext{
*Address for correspondence: Charles Hughes, Jr., Executive Director, Mississippi Council on Developmental Disabilities, 239 North Lamar St. \#1101, Jackson, MS 39201, USA. Tel.: +1 601 359 6238; Fax: +1 601359 6295; E-mail: charles.hughes@dmh. ms.gov.
}

with intellectual and developmental disabilities, like all individuals, have their own unique role in the cycle created by these state policies, programs, and services to promote "completion of schooling, movement from the parental household, entrance into the labor force," (Settersten, Furstenberg, \& Rumbaut, 2005). Though youth and young adults with intellectual and developmental disabilities share similar goals for independence, productivity, and employment as their peers without disabilities, the services needed to help them achieve these goals and successfully transition to life as an adult may be limited in scope, availability, and accessibility. Depending on their specific type of disability, youth and young adults in Mississippi may find it difficult to meet eligibility requirements for available services or find that needed services are simply non-existent. In addition, opportunities for competitive integrated employment that promote community inclusion are limited. 


\section{Background}

Mississippi, an historically and still primarily rural state with only five Standard Metropolitan Statistical Areas, has the highest poverty rate in the nation, $21.3 \%$. (U.S. Census, 2010). With a $37 \%$ African American population, the state also has the largest racial minority population in America (Statistical Abstract of the United States, 2010). Mississippi ranks fourth in the nation in the prevalence of disabilities of people of all ages, with $16.2 \%$ of the state's population having a disability (Disability Status Report, 2014).

In 2011 , only $65.9 \%$ of the state's working age population without a disability (1.6 million Mississippians between the ages of 16 and 64) were employed (Butterworth, et al., 2016). Of these working age Mississippians, 271,477 had any type of disability, and 117,184 had a cognitive disability. Employment rates for working age Mississippians with disabilities were significantly lower with $28.9 \%$ of people with any disability and $17.4 \%$ of those with a cognitive disability employed. Though employment rates for all Americans may have decreased or remained stagnant in recent years, research has suggested a bleak employment outlook for Mississippi's youth and young adults with disabilities due to the substantial decline in employment and educational opportunities for all people with disabilities.

The report, StateData: The National Report on Employment Services and Outcomes (Butterworth et al., 2016), revealed discrepancies in 2011 in mean annual earnings for working age people with no disability $(\$ 33,500)$, any disability $(\$ 27,400)$, and cognitive disability $(\$ 16,500)$. The report also revealed that poverty rates for working-age Mississippians differed by disability status with $18.7 \%$ of people with no disability, $31.4 \%$ of people with any disability, and $36.0 \%$ of people with a cognitive disability living below the poverty line.

During the 2010-2011 school year, $10.9 \%(53,675)$ of Mississippi's 490,970 public school students had a disability. Of these students with disabilities, 7.7\% had a disability that was not a speech/language disability and $4.23 \%$ had low incidence disabilities such as autism, developmental disabilities, or visual or hearing impairments (Mississippi Special Education District Data Profiles, 2011). During the 2004-2005 school year, only $28 \%$ of Mississippi students ages 14 to 21 served under the IDEA exited school by graduating with a regular high school diploma, a rate significantly lower than the $54 \%$ reported for the nation (U.S. Department of Education, 2010). This impacts employment outcomes for all students with intellectual and developmental disabilities. "Persons with a disability who had completed higher levels of education were more likely to be employed in 2010 than those with less education. However, at each level of education, persons with a disability were much less likely to be employed than were their counterparts with no disability" (Bureau of Labor Statistics, 2011).

In Mississippi, employment outcomes for people with disabilities vary widely. Both the Mississippi Department of Mental Health Bureau of Intellectual and Developmental Disabilities and the Mississippi Department of Rehabilitation Services provide employment services for people with intellectual and developmental disabilities. In 2011 , only $11 \%$ of the reported 2,950 individuals served by the Bureau of Intellectual and Developmental Disabilities were located in integrated employment settings while $27 \%$ were served in facility-based work (Butterworth, et al., 2016). In 2011, the Mississippi Department of Rehabilitation Services reported 9,792 case closures/employment outcomes with $991(10.1 \%)$ of these closures serving people with an intellectual disability. Of the 991 clients, 266 (20.7\%) were placed into employment (Butterworth, et al., 2016).

In June 2011, the Administration on Intellectual and Developmental Disabilities announced the availability of funds through the Projects of National Significance: Partnerships in Employment Systems Change grants to expand community employment in integrated settings for youth and young adults with intellectual and developmental disabilities. The grant availability provided an unprecedented opportunity to address the limitations related to education and employment of youth and young adults with intellectual and developmental disabilities in Mississippi. In July 2011, the Mississippi Developmental Disabilities Network, which includes the Mississippi Council on Developmental Disabilities, The University of Southern Mississippi Institute for Disability Studies (Mississippi's University Center for Excellence in Developmental Disabilities), and Disability Rights Mississippi, facilitated a grant development planning meeting with required agencies. After a review of the statistics on employment and a discussion, the consensus was that systems change efforts were necessary to address the barriers to and issues relating to integrated community employment, especially for youth and young adults with intellectual and developmental disabilities. In August 2011, a Memorandum 
of Understanding was signed by required agencies and other relevant organizations, as well as by two self-advocates. The Institute for Disability Studies took the lead to develop a grant proposal for the MSPE project.

\section{Goal}

The goal and primary focus of MSPE was to increase competitive employment outcomes for youth and young adults with intellectual and developmental disabilities in Mississippi through enhanced collaboration among existing state education and employment service systems. By engaging critical stakeholders in the collaborative process, the project sought to 1) develop policies; 2) remove systemic barriers; 3) implement strategies and best practices; and 4) improve the transition process for Mississippi youth and young adults with intellectual and developmental disabilities from school or training to competitive employment in integrated community settings.

\section{Consortium}

The Mississippi Council on Developmental Disabilities served as the lead agency for the MSPE grant. The University of Southern Mississippi Institute for Disability Studies and Disability Rights Mississippi served as managing partners. A broader Consortium was developed and continually expanded throughout the project. Consortium members ultimately included self-advocates and representatives who were knowledgeable about employment and/or youth and young adults with intellectual and developmental disabilities. Consortium members from relevant state systems included the Mississippi Department of Rehabilitation Services, Mississippi Department of Education, Mississippi Department of Employment Security, Mississippi Department of Mental Health, and Mississippi Division of Medicaid and advocacy representatives from The Arc of Mississippi, Client Assistance Program, Mississippi Parent Training and Information Center, and Mississippi APSE. An average of 20 participants attended the 20 quarterly Consortium meetings over the grant time period.

Participation by agency representatives was critical to the fulfillment of the grant for systems change. Agencies have typically operated without much consideration of what others are doing and data was not openly shared. The opportunity to bring the agency representatives together was a rather unique circumstance from how business was done in the past and critical to the success of the MSPE project. Over time, the Consortium members became more open to discussion and how they could assist with system change efforts. The key was having the right people "at the table." Nonetheless, it took time to develop relationships so stakeholders could share ideas for improving the systems and supports for people with intellectual and developmental disabilities. But while relationships were building, individual representatives began to make changes within their agencies. This was an unexpected surprise to have agencies take a more introspective and proactive approach. While more decision makers would have been beneficial, a lot of progress was made as shown in the outcomes and the sustainability of the grant. Several agencies have developed new Memoranda of Understanding to provide joint trainings and opportunities which would not have existed prior to the project.

\section{Work plan elements}

\subsection{Build capacity across existing state systems}

To improve outcomes for youth and young adults with intellectual and developmental disabilities seeking competitive integrated employment, the Consortium sought to promote meaningful and concrete changes to laws, policies, and practices. Based on reports provided by the Stakeholders Group, Employment Work Group, and Consortium members, each quarterly meeting provided opportunities for discussion of systems changes needed, such as increasing Medicaid buy-in on integrated employment, expanding 1915(i) services, educating employers of the benefits of hiring people with disabilities, ensuring that school districts provide sufficient work experience for every student, and making employment a key component in all person-centered planning across agencies.

One major area of emphasis was to provide leadership and guidance for Mississippi to become an Employment First state. After two failed attempts to pass legislation, a strategic meeting was held, with support of a state representative, a state senator, and representatives of the MSPE Consortium, to ask the Governor for an Executive Order to promote Employment First. The Governor signed Executive Order 1335 in 2014, which was based on the philosophy 
of Employment First. The Order reestablished a Disability Resource Commission which would provide annual updates to legislators on the status of employment of people with intellectual and developmental disabilities and offer recommendations to improve employment outcomes. A year later, legislation (House Bill 836) was passed and signed by the Governor. It reaffirmed items in Executive Order 1335 .

\subsection{Develop innovative strategies to remove systemic barriers}

The Consortium sought to determine existing barriers within the adult services system as youth and young adults transition to adulthood, such as a lack of policies regarding Employment First. Also, the state has few schools with a trained transition coordinator, a reliance on sheltered workshops, and a lack of coordination among agencies in providing services and supports needed by youth and young adults with intellectual and developmental disabilities for competitive integrated employment. In addition, a lack of knowledge required educating legislators and decision makers at agencies to increase their awareness and advocacy for improved employment outcomes.

Awareness was created through a variety of activities, including National Disability Employment Awareness Month, Mentoring Day, Employment First Day at the Capitol, Take a Legislator to Work Day, and Facebook/Twitter campaigns. Two media campaigns were used to promote employment of people with intellectual and developmental disabilities, one specifically focused on youth and young adults (television campaign).

Awareness also occurred within the Consortium. The first Consortium meeting was the first time agencies met together to focus on barriers in achieving competitive integrated employment for youth and young adults with intellectual and developmental disabilities. As agency representatives on the Consortium became more aware of services offered, a more open dialogue occurred. By the third year of the grant, agencies were conducting joint trainings and hosting events through several Memorandums of Understanding which were developed during this project. For example, the Mississippi Department of Mental Health Bureau of Intellectual and Developmental Disabilities crafted a Memorandum of Agreement with the Mississippi Department of Rehabilitation Services to enhance their supported employment services and improve efficiency of services provided. It enriched the collaborative and cooperative working relationship between the two agencies; established a state level workgroup to address system, policy, and funding issues; engaged stakeholders at local levels; identified and disseminated best practice information; and provided people with intellectual and developmental disabilities quality employment services that led to competitive integrated employment in a non-duplicative, seamless manner. In addition, job discovery was added to the state's Home and Community Based Waiver services. Also, joint trainings were held at the local level for staff of the Mississippi Department of Rehabilitation Services, Mississippi Department of Education, and the Mississippi Department of Employment Security to learn about services provided and to better meet the needs of people with intellectual and developmental disabilities.

\subsection{Identify and implement strategies and best practices}

A second ad hoc group was created early in the MSPE project. The Stakeholders Group was coordinated by the Institute for Disability Studies, which held 10 meetings over the project with an average attendance of 15 members. The group was established to focus on training and technical assistance needs, identify best practices, and promote organizational transformation and reallocation of resources for systems change. This group was made up of several Consortium members, plus educators, parents, and young adults. Statewide training and dissemination of information on strategies and best practices for self-advocates, family members, educators, policymakers, and the business community were needed to create awareness and knowledge of employment for young people with intellectual and developmental disabilities. For example, 16 community awareness training sessions were provided by Marc Gold \& Associates in each of the four Congressional districts across the state. Each session provided an overview of job development, customized employment, supported employment, federal laws and programs, environmental adaptations, person-centered planning services, and supports.

Other training activities across the state were conducted through in-person meetings, conferences, or webinars. These included topics such as assistive technology, accessible training methods, sequencing funds, Project SEARCH Southern Miss (The University of Southern Mississippi), transition best 
practices, Project ACCESS (Mississippi State University), Americans with Disabilities Act, customized employment, transportation, mentoring, postsecondary transition, self-advocacy, coaching strategies, social media, resources, services and supports. Over 5,600 people received training through this project.

In collaboration with the Stakeholders Group, the Institute for Disability Studies developed over 75 products including 10 videos. Also, the project produced a monthly video series called "Chit Chat Thursday with Taylor," hosted by a young adult selfadvocate, to highlight advocacy activities, services, and successes in Mississippi. In addition, Disability Rights Mississippi assisted in developing three videos on employment expectations, services, and transition. In 2012, MSPE launched the monthly "Live.WORK.Achieve" listserv newsletter to share best practices, news, training, success stories, and resources. Distribution increased each year with 125 recipients in 2012, 169 in 2013, and 204 in 2014. In 2015, MSPE combined with the STEP UP Notes listserv and nearly tripled the number of recipients enrolled to 574. Throughout the project, 66 listserv postings were shared. In 2014, MSPE issued a policy brief titled, "Hiring People with Disabilities is Good Business." This brief provided employment facts and examined ways in which Mississippi employers can benefit from hiring youth and young adults with intellectual and developmental disabilities. MSPE also developed an employment resources document and a fact sheet on the myths and facts about employing people with disabilities. Nineteen press releases promoting events and activities of MSPE were disseminated over the five-year project.

In addition to the Stakeholders Group work, training and resources provided, a pilot project was developed to provide innovative strategies to employment service agencies. The pilot project, operated by The Arc of Mississippi and titled "Customized Employment: Linking Job Seekers with Employers," used a network of provider agencies to increase training opportunities and use customized employment as a job development, training and support strategy. The project worked with three sheltered workshops and three high schools. Five people received assistance with the discovery process and two students received work experiences. The project staff learned that the process of moving people through the vocational rehabilitation system was quite complicated. The workshops were not reimbursed until a benchmark was completed, which resulted in a challenge to pay staff before the levels were achieved. As a result of these experiences, a Memorandum of Agreement between the Mississippi Department of Rehabilitation Services and the Mississippi Department of Mental Health was developed to speed up the referral process for people with intellectual and developmental disabilities and assist them to explore employment options. Other items in the Memorandum of Agreement are listed in the Select Outcomes section.

\subsection{Enhance collaborations for transition}

Pilot projects to promote innovative transition strategies in high school were determined through a request for proposals process. The applicant was expected to provide students with employment experiences while in school and assist them in finding competitive employment. The MSPE managing partners approved funding for two pilot locations in 2012, the Oxford School District and the Rankin County School District.

The Oxford School District project, "BOLTS: Building Opportunities for Learning and Transition Success," included a high school-based training program with greenhouse and pottery activities, and community-based training with internships which allowed students to move into full- or part-time employment. Some students participated in an entrepreneurial program to raise tomatoes for use in the school cafeteria and sell to the general public. Middle school students also participated in operating a store on campus. Over the three years of the project, BOLTS assisted 52 students to find employment in the community. As part of systems change, BOLTS is using the Smart Work Ethics Train-theTrainer Program and offers training to other schools across the state at no cost. In addition, to address transportation needs of students trying to get to work, bus stops were added to the public bus routes, which included a bus stop at the high school. BOLTS staff members have developed a manual to help other sites implement similar projects. The BOLTS project will continue beyond the grant period with the support of the school district.

The Rankin County School District pilot project was called "Gathering Grounds." Gathering Grounds is a community-based business where students with disabilities learn to work and develop social skills. The business includes a coffee shop operation, coffee cart kiosk operation, and sales of items such as art work, pottery, t-shirt graphics, or embroidery. Over the three years of this pilot project, 30 students obtained employment out in the community. Several 
students participated in disability awareness activities at the state capitol and in a media campaign promoting employment of people with disabilities. Gathering Grounds staff members have developed a guide for implementation and are sharing their story at several conferences across the state. Gathering Grounds is receiving district support for the schools involved to continue beyond the MSPE grant period.

\section{Select outcomes}

Outcomes for MSPE included 1) changes in policies and procedures by agencies and government; and 2) changes in knowledge, attitude, and awareness of employment for youth and young adults with intellectual and developmental disabilities by self-advocates, family members, educators, policymakers, and the business community. All of the significant outcomes were a result of the collaborative partnerships developed throughout the project.

In 2012, the MSPE Employment Work Group's goals included developing strategies to promote Employment First in the state. In 2013, this work group helped draft Employment First legislation which was introduced in both the Senate and the House. Although the legislation did not pass the first two attempts, MSPE advocacy and awareness efforts helped lay the foundation for future policy change. During the Disability Employment Partnerships Awareness Day at the Capitol in January 2014, the Governor signed an Executive Order which would reactivate the Disability Resource Commission. With support from a legislative champion, Employment First legislation passed unanimously in the Mississippi House of Representatives but did not move out of Senate committee. Legislation was introduced again in 2015 and passed both the Mississippi House of Representatives and Senate, with the Governor signing the Mississippi Competitive Employment Act in April 2015.

To facilitate an initial meeting of the Disability Resource Commission, the MSPE managing partners met with executive directors from the key state agencies to familiarize them with the Disability Resource Commission and requested an appointment from each. Letters were sent to them and also to elected officials needing to make their appointments. Only three of the 13 individuals needed have been named to the Disability Resource Commission as of December 2016.
In June 2015, the Mississippi Department of Rehabilitation Services Office of Vocational Rehabilitation and the Mississippi Department of Mental Health Bureau of Intellectual and Developmental Disabilities signed a Memorandum of Agreement focused on expanding employment opportunities for people with intellectual and developmental disabilities. The agencies adopted a new referral method for the Mississippi Department of Mental Health to refer people with disabilities who want to work to the Office of Vocational Rehabilitation. The Memorandum of Agreement promotes collaboration for staff certification, monitoring and training standards; working to increase the number of service providers; achieving seamless transition with intellectual and developmental disabilities waiver services and vocational rehabilitation services funds; and requiring a minimum of semi-annual meetings between agencies; offering cross agency training opportunities. Since the agreement was finalized, over 200 service coordinators, targeted case managers, and vocational counselors have received training to learn more about waiver services and vocational rehabilitation services. One key component of the training was that local staff providing these services got to meet one another to better serve their clients in the future.

The Mississippi Department of Employment Security modified the language in job announcements to make them more inclusive of people with disabilities. The agency reviewed its website and WIN Job Centers across the state for physical and service accessibility. Internships for people with disabilities were also created within the agency. Since the program began, three individuals referred from AbilityWorks participated and one was hired full-time.

At the beginning of the MSPE project, an older Memorandum of Understanding between the Mississippi Department of Employment Security and Mississippi Department of Rehabilitation Services was uncovered. It included language to promote Governor's Job Fairs in the state. Since that time, three Annual EmployAbility Job Fairs have been conducted. In 2014, more than 650 people attended, and 60 job offers from 33 employers were given. In 2015 , more than 400 attendees participated, resulting in 88 job offers from 46 employers. In 2016, more than 500 people attended with 82 jobs offers from 40 employers.

The Mississippi Department of Education policy revisions included the addition of a vocational assessment for children ages 14 and above, and the requirement for a summary of academic achievement 
and functional performance upon exiting high school. The agency partnered with the Mississippi Department of Rehabilitation Services for training opportunities on a local level to ensure staff members from each agency know one another and collaborate in the future. With implementation of the Workforce Innovation and Opportunity Act (WIOA), agencies will continue to collaborate both on initiatives started by MSPE and those required through WIOA.

\section{Sustainability}

The Employment First Executive Order and legislation (House Bill 836) included reactivation of the Disability Resource Commission, which set the foundation for continuation of MSPE work beyond the grant. This will be a mechanism to monitor employment of youth, young adults, and others with disabilities, and to provide recommendations to the Governor and legislators on a yearly basis. The MSPE managing partners will continue to encourage appointments and coordinate initial meetings of the Disability Resource Commission.

Several members of the Consortium serve on the board and planning committee for the Mississippi disAbility MegaConference. This non-profit group started five years ago and is coordinated by 10 disability organizations. Approximately 450 individuals with disabilities, family members, and professionals attend the conference each year. Employment has been a featured topic of discussion in at least three concurrent sessions each year. In addition to these sessions, national leaders from the U.S. Department of Labor's Office of Disability Employment Policy, the U.S. Department of Education's Office of Special Education of Rehabilitation Services, and the Association of University Centers on Disabilities have presented as keynote speakers. For 2017, the project director of the MSPE grant will serve as president of the board for the Mississippi disAbility MegaConference and on the program committee, which will ensure that several sessions about employment of people with disabilities are included over the next two years as part of the MegaConference.

The Mississippi Council on Developmental Disabilities, in collaboration with the Institute for Disability Studies, is assisting in the revitalization of the Mississippi Association of Higher Education and Disability, which became inactive three years ago mainly due to lack of leadership. Disability support staff members at eight public universities, five private universities, and 15 community colleges have expressed the need for training to better serve students with all types of disabilities. As the trend continues to include people with intellectual and developmental disabilities on the post-secondary level, now is the critical time to start providing needed resources and training for disability accommodations to higher education staff, instructors, professors, administrators, and others. The Mississippi Council on Developmental Disabilities will assist in providing or supporting the training events.

Consortium members will continue to participate in the Mississippi state chapter of the Association of People Supporting Employment First (APSE). This organization promotes the employment of people with disabilities in competitive work in integrated settings. One Consortium member served on the Mississippi APSE board. Consortium members have presented at several state and national conferences of organizations such as APSE, the Association of University Centers on Disabilities, and the National Association of Councils on Developmental Disabilities. As a result, professionals and advocates from other states have received information about MSPE and how the grant was implemented to assist them as they develop their own employment initiatives.

MSPE Consortium members will continue to participate on task forces and other related efforts to impact policies that will improve employment outcomes for people with intellectual and developmental disabilities. Four Consortium members also serve on the Mississippi Council on Developmental Disabilities as self-advocates and agency representatives. At least five members are directly involved with changes within their organizations to implement the Workforce Innovation and Opportunity Act, administer the Home and Community Based Services (HCBS) Waivers and Medicaid 1915(i) programs, and other related initiatives. Agencies will continue to offer the annual Governor's Job Fair for Individuals with Disabilities.

Since 2012, the Council has funded 10 initiatives related to employment of youth and adults with intellectual and developmental disabilities. This includes Project SEARCH at The University of Southern Mississippi, a school-to-work program which takes place on the university campus. Students with intellectual disabilities receive a combination of classroom instruction, career exploration, and hands-on training through worksite rotations. Once their training program is complete, it is anticipated that many of these students will be hired at their work experience 
sites or elsewhere in their communities. Seven students participated during the first year. Three of them obtained full-time employment, two participated in national service, and two received further training which included some income. Eleven students are enrolled in the second year of Project SEARCH. Expectations are high for them to complete their internships and obtain employment.

The Mississippi Council on Developmental Disabilities will also maintain relevant web-based information. The Mississippi Community Resource Directory is a searchable database to find resources across the state. Videos, newsletters, and other products from the MSPE project will continue to be available on the Mississippi Council on Developmental Disabilities' and MSPE project's websites. The Institute for Disability Studies will maintain the MSPE website. This will allow continued sharing of employment information for people with disabilities, families, and others in the community.

The Oxford School District and Rankin County School District will continue to provide their transition projects for students with intellectual disabilities. These programs will continue to serve as models for other school districts to consider. Teachers trained in "Smart Work Ethics" will continue to share their knowledge, free of charge, to other teachers across the state. The Oxford School District program will continue to collaborate with the University of Mississippi in providing a transition course to better prepare future educators. Videos from both projects will continue to be available, and implementation manuals of the projects will continue to be disseminated.

\section{Conclusion}

The Mississippi Partnerships for Employment's Consortium members maintained a clear focus throughout the grant life. Without the ongoing collaboration and open dialogue of project partners as the grant evolved, most of the accomplishments achieved would not have been possible. In retrospect, there would be no Executive Order or legislation signed by the Governor regarding employment of people with intellectual and developmental disabilities; no interagency Memorandums of Understanding between key state agencies to provide joint agency trainings or disability awareness events to improve employment and educational outcomes for youth and young adults with intellectual and developmental disabilities; less emphasis on employment by Medicaid and waiver services; no exceptional transition service programs at two major school districts with students gaining community employment; and thousands of Mississippians, including people with disabilities, family members, professionals, legislators, and others would not have learned about best practices in transition to competitive integrated employment.

The focus remained on how organizations could collaborate to make positive statewide systems change around employment of youth and young adults with intellectual and developmental disabilities. The collaboration was based on several common values, including the idea that all young people should have an equal opportunity for meaningful employment and productive lives in the community as citizens of Mississippi. Consortium partners agree that youth and young adults with intellectual and developmental disabilities should be able to display and voice their competencies, capabilities and personal goals as they transition throughout life, whether at school or work and that these youth and young adults be recognized, supported and encouraged to live out their dreams for a life in their communities.

\section{Conflict of interest}

None to report.

\section{References}

Bureau of Labor Statistics. (2010). Persons with a disability: Labor force characteristics [Press release]. Retrieved from https://www.bls.gov/news.release/archives/disabl_06242011. pdf

Butterworth, J., Smith, F. A., Hall, A. C., Migliore, A., Winsor, J., Domin, D., \& Timmons, J. C. (2016). StateData: The national report on employment services and outcomes. Boston, MA: University of Massachusetts Boston, Institute for Community Inclusion.

Disability Status Report United States. (2014). Cornell University Disability Status Report [Data File]. Retrieved from http://www.disabilitystatistics.org/

Individuals with Disabilities Education Act, 20 U.S.C. $\S 1400$ (2004)

Mississippi Department of Education. (2010). Special education data district profiles [Data File]. Retrieved from http://ww.w.healthyschoolsms.org/OSE/DD/district-data2010-2011/page/7/5ae853e9-1ff1-4d7c-82fe-ba3f976f7615

Settersten, R., Furstenberg, F., \& Rumbaut, R. (2005). On the frontier of adulthood (p. 7). Chicago, IL: The University of Chicago.

Statistical Abstract of the United States. (2010). Statistical Abstract of the United States [Data File]. Retrieved from 
http://www.census.gov/library/publications/2009/compendia/ statab/129ed.html

United States Census. (2010). Census data [Data File]. Retrieved from http://www.census.gov/2010census/

United States Department of Education. (2010). The condition of education 2010. Retrieved from http://nces.ed.gov/ pubs2010/2010028.pdf
United States Department of Labor. (2014). Youth employment rate. Retrieved from https://www.dol.gov/odep/categories/ youth/youthemployment.htm 